\title{
Mechanical Behavior and Microstructural Analysis of Molybdenum- TZM Alloy Subjected to Different Annealing Temperature.
}

\author{
Muhamad Anas Munawwar Ghazali ${ }^{1}$, Mohd Azhar Harimon ${ }^{1}$, Mohammad Sukri Mustapa ${ }^{1}$ \\ ${ }^{1}$ Faculty of Mechanical and Manufacturing Engineering \\ Universiti Tun Hussein Onn Malaysia (UTHM).
}

\begin{abstract}
Mo-TZM alloy is one of the most famous economic molybdenum-based alloys. The percentage of chemical composition in mass of Mo-TZM alloy are Mo-0.5Ti-0.08Zr-0.03C. By adding some Titanium and Zirconium so that the mechanical properties and recrystallization temperature of molybdenum has been corresponding improvement. The purpose of this study is to determine the effect of different annealing temperature on mechanical properties of Mo-TZM alloy. The samples will be heated at two different temperature which are $1000^{\circ} \mathrm{C}$ and $1300^{\circ} \mathrm{C}$ in 1 hour and 40 minutes to change their microstructure behavior. The mechanical properties of the sample like hardness will be analyzed by using Vickers Micro hardness test. The force applied is $4.903 \mathrm{~N}$ and Vickers micro hardness number is $0.5 \mathrm{HVN}$ for 10 second. Then to observe the microstructure changes, optical microscope and Scanning Electron Microscope (SEM) is be used. At annealing temperature $1000{ }^{\circ} \mathrm{C}$, it show values of hardness is $249.54 \mathrm{VHN}$ and the grain boundary size is $0.0898 \mathrm{~mm}$. While at annealing temperature $1300{ }^{\circ} \mathrm{C}$, it show the lowest values of hardness which is $243.55 \mathrm{VHN}$ and the highest grain boundary size which is $0.1068 \mathrm{~mm}$. By doing annealing heat treatment it will decreases hardness values and increases the size of grain boundary.
\end{abstract}

Keywords: Mo-TZM alloy, Heat treatment, Microstructure, Grain size, Hardness.

\section{Introduction}

In the previous few decades, the application for hightemperature materials has been used extensively and there is at the same time demand for high working temperature. Due to their high melting temperature $\left(2622{ }^{\circ} \mathrm{C}\right)$, molybdenum and its alloys are often manufactured by powder metallurgy[1]. It's capable of withstanding the aggressive environment with respect to stress, radiation, liquid metal corrosion at high temperature. Mo-TZM alloy (Titanium-Zirconium-Molybdenum) is one of the most famous economic molybdenum-based alloys. It is generally used as a structural material in thermally loaded applications or as plate material in rotary X-ray tubes. Compare to pure molybdenum Mo-TZM exhibits a higher strength and creep resistance [2]. Mo-TZM alloy consists of (0.40-0.55) wt. \% Ti, (0.06-0.12) wt. \% Zr, (0.01-0.04) wt. \% very fine carbides $\mathrm{C}$ and Mo in balance [3]. By alloying molybdenum with titanium and zirconium element, the mechanical properties and recrystallization temperature of molybdenum has been the corresponding improvement. By alloying molybdenum with titanium and zirconium element, the mechanical properties and recrystallization temperature of molybdenum has been the corresponding improvement.

Mo-TZM alloy has many excellent physical and chemical properties which are density $\left(10.22 \mathrm{~g} / \mathrm{cm}^{3}\right)$, melting point $\left(2617^{\circ} \mathrm{C}\right)$ and boiling point $\left(4612^{\circ} \mathrm{C}\right)$. The starting recrystallization temperature of Mo-TZM alloy is about $900{ }^{\circ} \mathrm{C}$ and end recrystallization temperature is $1700{ }^{\circ} \mathrm{C}$ [2]. The small amount addition of $\mathrm{Ti}$ and $\mathrm{Zr}$ has strengthened molybdenum solid solution due to the dispersion of composite carbides in the molybdenum matrix by the formation of precipitates of $\mathrm{TiC}$ and $\mathrm{ZrC}$ [4]. However, compared with the Mo-TZM alloy, molybdenum recrystallization temperature and strength is low and brittleness is large, so molybdenum application range is limited. Mo-TZM alloy is based on molybdenum matrix to add a small amount of $\mathrm{Zr}$, $\mathrm{Ti}$, and $\mathrm{C}$ elements. These finely dispersed particles can prevent molybdenum grain growth possibility at high temperature [5]. Thereby increasing the recrystallization temperature of the alloy, making alloy's properties has been greatly improved.

\section{Experimental}

In the present study, the specimen is produced by Metal Injection Molding (MIM) that is one type of conventional process in powder metallurgy. The composition of this Mo-TZM alloy is (0.49) wt. \% Ti, (0.068) wt. \% Zr, (0.079) wt. \% very fine carbides $\mathrm{C}$ and Mo in balance. The sample has come with the shape single edge notch beam (SENB) specimens were machined from the forged blocks in the longitudinal direction, where the notch direction was parallel to the forging direction. Then it will be cut to divide by two by using Electric Discharge Machine (EDM) wire cut. The size of the test sample is $15 \times 5 \times 5 \mathrm{~mm}$. This because the 
new dimension for this specimen is suitable for test conducting which is Vickers hardness that needs a small specimen to be tested.

In this study, the specimen is heat treated, which is an oven used for annealing process using a tube furnace. The process to heat the specimen is known as stress relief annealing [6]. Annealing is a process of heating the specimen to a predetermined temperature, holding at this temperature, and finally cooled in room temperature air with natural convection. The temperature that has been selected for the annealing process is $1000{ }^{\circ} \mathrm{C}$ and 1300 ${ }^{\circ} \mathrm{C}$. The holding time at each temperature for every specimen is 1 hour and 30 minutes and heating rate for each specimen was $10^{\circ} \mathrm{C} / \mathrm{min}$. Figure 1 shows the heating curve of this study.

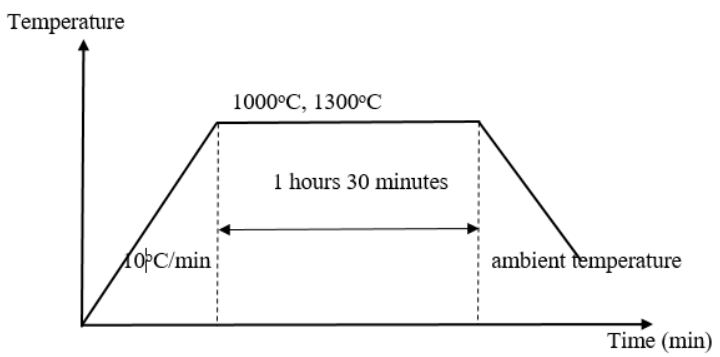

Figure 1: Heating curve.

Mechanical testing is a term that cover a wide range of test, which can be divided into two type which are those that aim to determine a mechanical properties of the material and to determine the response of a structure to a given action. For this study, only one types of mechanical testing need to be done which is Vickers Micro hardness testing. Vickers micro hardness has been used to test the hardness of the sample. In order to obtain the accurate result, the test will be done at least four times at different point on the surface of each sample to get the average data. The test was indented under load of $4.903 \mathrm{~N}$ $(0.5 \mathrm{HVN})$ within 10 second with flat shape for 4 times.

The images from the OM can be snap by a very sensitive light cameras that are used to generate micrographs and digital images. The images will be viewed directly through the computer screen. This microscope has magnification range of $5 x$ up to $100 x$. The specimen need first to be done grinding and polishing and also need to be etch for at least 30 second to make sure the microstructure on the surface will appear when see through the OM. In this study, the acid solution used in etching were $30 \mathrm{ml}$ of phosphoric acid, $18 \mathrm{ml}$ of nitric acid, $10 \mathrm{ml}$ of acetic acid and $65 \mathrm{ml}$ of distilled water [7]. Lastly, Scanning Electron Microscope were used to analyzed the composition

\section{Results and Discussion}

The result from each testing have been recorded and interpreted by using a suitable graph and microstructure image to determine the effect of heat treatment temperature toward microstructure and mechanical properties of Mo-TZM alloy with different annealing temperature. Microstructure observation in this study is done by optical microscope $(\mathrm{OM})$ to determine the effects of heat treating temperature toward microstructure of the sample. Meanwhile, Vickers micro hardness test been done in this study to determine the effect of heat treating temperature toward mechanical properties. Lastly, composition observation has been done in this study to determine the effect of furnace while the heat treatment experiment is going.

\subsection{Hardness Test}

The hardness test use in this study is a Vickers hardness test which is a standard method for measuring the hardness of the metal because metal have hard surface.

The values obtained directly from the Vickers micro hardness test machine. A total of 9 samples were used, which had 2 different temperature and were represented by $\mathrm{S} 1, \mathrm{~S} 2, \mathrm{~S} 3, \mathrm{~A} 1, \mathrm{~A} 2, \mathrm{~A} 3, \mathrm{~B} 1, \mathrm{~B} 2$, and B3. A total of 6 samples represented by samples $\mathrm{A}$ and $\mathrm{B}$ were underwent heat treatment at temperatures of $1000^{\circ} \mathrm{C}$ and $1300^{\circ} \mathrm{C}$ at the same time rate of 1 hour 40 minutes and 3 samples represented by $\mathrm{S}$ were left alone in room temperature. In this test, sample $\mathrm{S}$ has been used as a control sample for reference and every sample has been taken 4 readings so that average reading can be obtained. Figure 2 shows the average result of each sample.

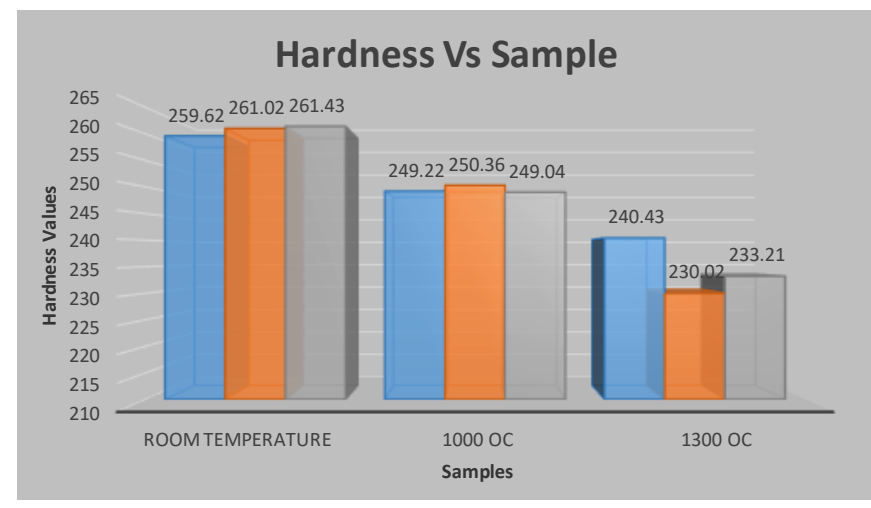

Figure 2: Bar graph hardness values against the sample.

Through by hardness tests conducted on the control sample, the values obtained for sample S1, S2, and S3 are 259.62, 261.02, and 261.43 respectively. The hardness value that were obtained has been used as a reference for comparison to determine the mechanical properties of this study. This control sample was left at room temperature while the other sample that need to be compared had undergone heat treatment. It is found that the hardness of the sample that undergoing annealing temperature heat treatment has low hardness value from the control sample which is sample $\mathrm{S}$. 


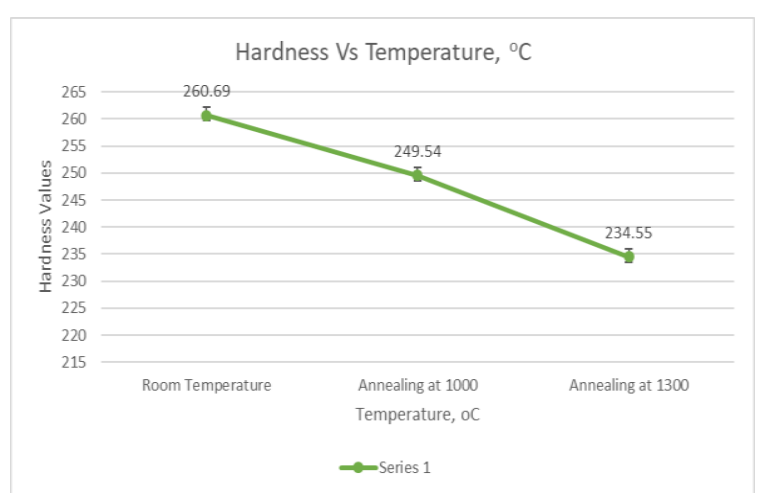

Figure 3: Hardness values versus temperatures.

According the data that obtain, the value of hardness of sample have been plot in the graph that shown in Figure 4.2 which is hardness value versus temperature. The graph shows that hardness values decreases directly proportional with different annealing temperature. The hardness of Mo-TZM alloy can be lowered when annealing treatment is applied. The lowest average values of the hardness in this study is $234.55 \mathrm{HVN}$ which belong to group B that undergoes annealing temperature at $1300^{\circ} \mathrm{C}$. Meanwhile the highest value of the hardness is 260.69 HVN and that belong to group $\mathrm{S}$ which is the specimen not undergoes annealing treatment.

Temperature is the biggest influence in the change of the mechanical properties of a substance. At annealing temperature $1000^{\circ} \mathrm{C}$ with a time of 1 hour 40 minutes it showing that it had a larger grain boundary than the sample at room temperature. This has caused the lower hardness values than sample without undergoes annealing treatment. At annealing temperature of $1300^{\circ} \mathrm{C}$, its hardness values is lower than the sample which has been undergoes annealing temperature of $1000^{\circ} \mathrm{C}$. This happens because the boundary of the grain formed is larger. At this moment, the high ductility behavior of the sample is produced and it will reduce the hardness value of the sample [8]. Based on the theory, annealing in metallurgy is a heat treatment that alters the physical and sometimes chemical properties of a material to increase it ductility and reduce its hardness, it will making this sample more workable. In annealing, the atoms migrate in the crystal lattice and the number of dislocation decreases, leading to change in ductility behavior and hardness value. This can be prove by previous study, $\mathrm{T}$. Mrotzek had found that by increase the annealing temperature at $1300^{\circ} \mathrm{C}$, the hardness of the sample will be drop [1]. From the study conducted, this theory has been proven by the results taken from the Vickers micro hardness test that have been conducted.

\subsection{Microstructure Analysis}

In this study, the microstructure behavior of MoTZM alloy is analyzed by using Optical Microscope $(\mathrm{OM})$. This microstructure observation is to visualize the grain boundary of Mo-TZM alloy. In the microstructure analysis one of the important factor that affecting the mechanical properties is the shape of grain boundary. This is because alloys that have uniform and smooth shapes are stronger and harder than those of an alloy that have an obscure and rough shape. The magnification used for this microstructure observation is $20 \mathrm{X}$.

Table 1: Microstructure of Mo-TZM alloy.

\begin{tabular}{|c|c|}
\hline Condition & Image \\
\hline $\begin{array}{c}\text { At room } \\
\text { temperature }\end{array}$ & \\
\hline & \\
\hline $\begin{array}{c}\text { Annealing at } \\
1000^{\circ} \mathrm{C}\end{array}$ & \\
\hline $1300^{\circ} \mathrm{C}$ & \\
\hline & \\
\hline
\end{tabular}

Based on the table 1 it show the microstructure of Mo-TZM alloy with different temperature. As seen from the table, the grains for the present three material are almost equiaxed shape. Equiaxed shape can be achieved by heat treatment, such as annealing and normalizing [9]. As the microstructure image at room temperature, it shows that groups $\mathrm{S}$ have constantly uniform equiaxed shape. It have been prove when sample at group $S$ have highest values of hardness test. This is because the uniform shape of grain boundary can make the sample more hardness and brittle. Besides that, microstructure image at annealing $1000^{\circ} \mathrm{C}$ also show almost constantly uniform equiaxed shape. The hardness value of groups A show a lit bit lower that groups $\mathrm{S}$ because the grain boundary shape of groups $\mathrm{A}$ is not uniformly as groups $\mathrm{S}$. For microstructure image at annealing $1300^{\circ} \mathrm{C}$, its show that the grain boundary shape at this groups B are not perfectly uniform. This will affect the hardness value of sample groups B that have the lowest value of the hardness test. According to the theory of hardness mechanisms, the uniformity of phase formation finds a 
very important role in the formation of good mechanical properties [10]. This will happens when the grain boundary shape has formed smooth and uniform.

After metallographic sample preparation, grains boundary in a Mo-TZM alloy are often analyzed by microscopy, where the size and distribution of these grains boundary can demonstrate the integrity and quality of the sample. In this study, the size of grain boundary were analyses by using Grain Intercept ASTM E1382. For this analysis 10x objective lens is require.

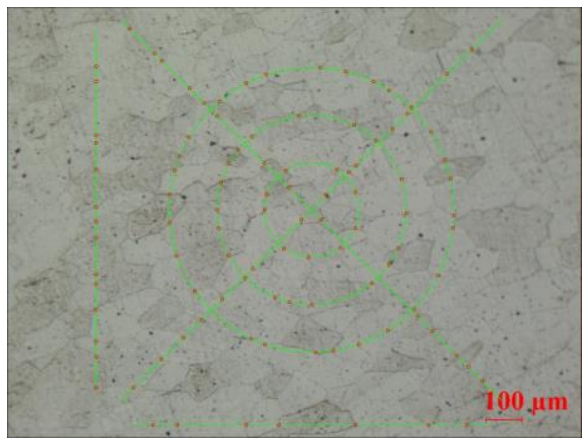

Figure 4: Grain size analysis for sample at room temperature.

Table 2: Grain size result.

\begin{tabular}{|ccccc|}
\hline Sample & $\begin{array}{l}\text { Grain } \\
\text { Boundary } \\
\text { Intercepts }\end{array}$ & $\begin{array}{l}\text { Mean } \\
\text { Intercept } \\
\text { Length }\end{array}$ & $\begin{array}{l}\text { G } \\
\text { number }\end{array}$ & $\begin{array}{l}\text { Average } \\
\text { Diameter }\end{array}$ \\
\hline $\begin{array}{c}\text { Room } \\
\text { temp. }\end{array}$ & 153 & 66.01 & 4.55 & $75.5 \mathrm{um}$ \\
\hline $1000^{\circ} \mathrm{C}$ & 134 & 75.37 & 4.17 & $89.8 \mathrm{um}$ \\
\hline $1300^{\circ} \mathrm{C}$ & 104 & 98.05 & 3.44 & $106.8 \mathrm{um}$ \\
\hline
\end{tabular}

Based on the figure 4 its shows the grain intercept on the pattern in the sample at room temperature. From the analysis that have done, the number of grain boundary intercepts is 153 and mean for intercept length is 66.01. The $\mathrm{G}$ number for this analysis is 4.55 and it can convert to average diameter which is $75.5 \mathrm{um}$. The size and level of uniformity of these grain boundaries act to help Mo-TZM alloy be stronger and harder. Through a mechanical test it was found that samples that did not undergo annealing heat treatment had high strength and hardness. This can be proved by diagram 4 where size grain boundary on the sample is smaller.

From the table 2 its shows the grain intercept on the pattern in the sample at $1000 \mathrm{oC}$ annealing temperature. From the analysis that have done, the number of grain boundary intercepts is 134 and mean for intercept length is 75.37. The $\mathrm{G}$ number for this analysis is 4.17 and it can convert to average diameter which is $89.8 \mathrm{um}$. From the surface of the sample it is found that the grain boundary size formed is smooth and only a small size of large grain boundary exists. Due to the large grain boundary size formed, it has affected the mechanical properties of the sample. This is evidenced by previous hardness values, where the sample in group A has a low hardness value compared to the sample in group $\mathrm{S}$.

From the table 2 its shows the grain intercept on the pattern in the sample at $1300{ }^{\circ} \mathrm{C}$ annealing temperature. From the analysis that have done, the number of grain boundary intercepts is 104 and mean for intercept length is 98.05 . The $\mathrm{G}$ number for this analysis is 3.44 and it can convert to average diameter which is $106.8 \mathrm{um}$. Based on the observation in table 1, the size grain boundary in the group samples B is larger than the size grain boundary in sample A and sample $\mathrm{S}$. This can be supported by the mechanical properties of the sample group because in the hardness test conducted, the sample group B has a low hardness value.

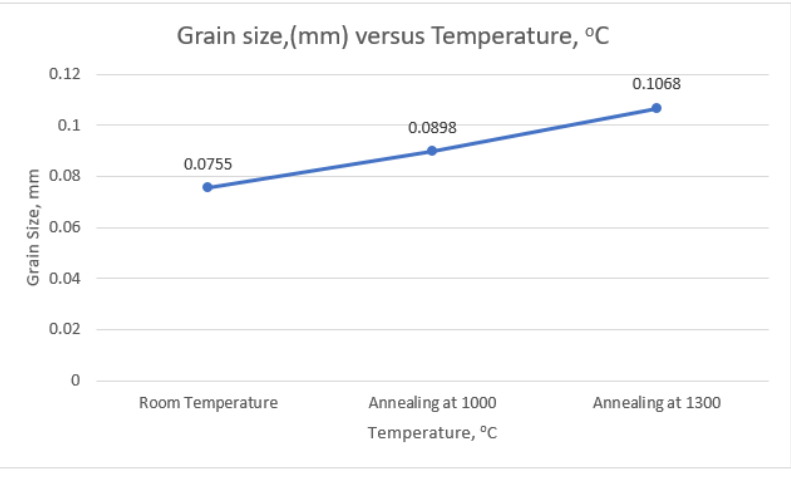

Figure 5: Line graph grain size, mm versus temperature, ${ }^{\circ} \mathrm{C}$

Based on the analysis performed on the size of grain boundary in each sample group, it can be concluded by doing the line graph. From figure 4-6 it is found that the sample group undergoing annealing heat treatment has a larger grain boundary than the sample group which is left at room temperature. The line graph show that the grain size is directly proportional to annealing temperature. This is because different annealing heat treatment process has changed the size of grain boundary. Based on previous studies, V.V. Buchanovsky have found when increases in annealing temperature it cause the grain growth and annealing temperature heat treatment has reached recrystallization level for Mo-TZM alloy then change the size of the sample [11]. Lastly, the higher the annealing temperature the larger the grain boundary size.

\section{EDS Analysis}

Energy Dispersive Spectroscopy (EDS) is an analytical technique used for the elemental analysis or chemical characterization of a sample. In this study, this machine is used to analysis element on the sample before and after the metallurgy preparation. This is because the presence 
of other elements in the sample will affect the mechanical properties itself. EDS test have been done for all the group of sample.

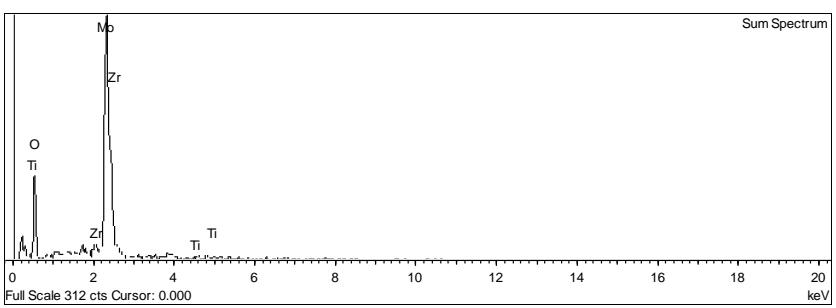

(a)

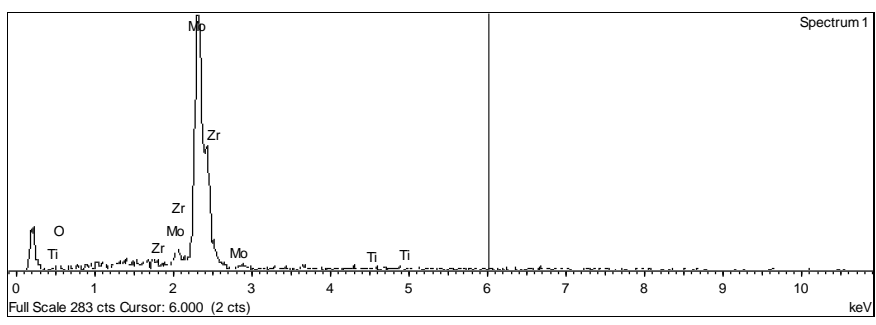

(b)

Figure 6:EDS analysis for sample at $1000^{\circ} \mathrm{C}$ annealing temperature (a) before (b) after sample preparation.

Figure 6 (a) was illustrated the existence of $\mathrm{Mo}, \mathrm{Zr}$, Ti and $\mathrm{O}$. There were a lot amount of Oxygen in the sample before sample preparation but at figure $4-9$ (b) the amount of Oxygen have been decrease. This because, when metallurgy preparation have been done it have remove the oxygen layer by using polishing. The existence of Oxygen have come by doing the annealing temperature by using tube furnace.

\section{Summary}

This research can be conclude that achieved the objective of the research because successfully determine the effect of different annealing temperature on hardness properties of Mo-TZM alloy and analyses the microstructure of Mo-TZM alloy before and after being subjected to different annealing temperature. The optimum annealing temperature for this research is $1300^{\circ} \mathrm{C}$. This is because when using this annealing temperature, the mechanical and microstructure properties of Mo-TZM alloy can be downgrade for appropriate use.

\section{References}

[1] Mrotzek T, Hoffmann A and Martin U 2006 Hardening mechanisms and recrystallization behaviour of several molybdenum alloys Int. J. Refract. Met. Hard Mater. 24 298-305

[2] Mrotzek T, Martin U and Hoffmann A 2010 High temperature deformation behavior of the molybdenum alloy TZM J. Phys. Conf. Ser. 240 $0-4$

[3] Harimon M A 2017 High Temperature Fracture Toughness and Fatigue Behavoir of Ti-Zr-Mo and W-Re Alloys for X-ray Tube Application. (Nagaoka University of Technology)

[4] Stanislav Naboychenko Handbook of NonFerrous Metal Powders ed S N Mourachova (Elsevier Science)

[5] Morito F 1994 Effect of heat treatment on the microstructure and the mechanical behavior of TZM alloy J. Nucl. Mater. 212-215 1608-12

[6] B.N.SinghaJ.H.EvansbA.HorsewellaP.ToftaD.J. Edwardsa1 1995 Microstructure and mechanical behaviour of TZM and Mo-5\% Re alloys irradiated with fission neutrons 223 95-102

[7] Zeng H C 1998 Chemical Etching of Molybdenum Trioxide: A New Tailor-Made Synthesis of MoO 3 Catalysts 1994 1967-73

[8] PingHuaFanYangaKuai-SheWangaZhitaoYuaJiang-feiTanaRuiSongaBo-liangHu 2015 Preparation and ductile-to-brittle transition temperature of the La-TZM alloy plates 52 1316.

[9] Han J, Semiatin S L and Soo C 2008 Hightemperature deformation and grain-boundary characteristics of titanium alloys with an equiaxed microstructure 485 601-12

[10]E. G D 1988 Mechanical Metallurgy

[11]Buchanovsky V V and Polishuk E P 2007 THE EFFECT OF HEAT TREATMENT ON MECHANICAL 46 233-6 